Research Article

\title{
Study on ETFEE in the BTH Region Based on the Window-SBM-Undesirable Model
}

\author{
Feng Ren (D), Xin Yu, and Quan Li \\ School of Business and Administration, North China Electric Power University, No. 689, Huadian Road, Lianchi District, \\ Baoding 071003, Hebei, China
}

Correspondence should be addressed to Feng Ren; renfeng2002@126.com

Received 3 April 2020; Revised 29 July 2020; Accepted 4 August 2020; Published 6 October 2020

Guest Editor: Fuqiang Gu

Copyright (c) 2020 Feng Ren et al. This is an open access article distributed under the Creative Commons Attribution License, which permits unrestricted use, distribution, and reproduction in any medium, provided the original work is properly cited.

Research on ecological total-factor energy efficiency (ETFEE) is conducive to energy conservation, emission reduction, and ecological protection. This paper focuses on the measurement and decomposition of the ETFEE in the Beijing-Tianjin-Hebei (BTH) region in China. In order to measure the ETFEE values, the window technology is combined with a nonradial and nonoriented SBM-undesirable model considering undesirable outputs to overcome the defect of insufficient data of research objects and ensure the calculation process to be implemented. The findings show that Beijing and Tianjin are DEA-efficient, while Hebei is not. The technological progress rates of Beijing and Tianjin reach up to $11.92 \%$ and $14.96 \%$, while that of Hebei retrogresses by $4.47 \%$. The scale efficiencies of Beijing, Tianjin, and Hebei are $97.75 \%, 86.60 \%$, and $93.81 \%$, respectively, which means that there are potentials for further optimization in the energy structures. The impulse response results between the energy structure and the ETFEE show that the proportions of coal and petroleum have negative effects on the ETFEE, while that of natural gas has a positive effect. The research results can provide reference for decision makers to formulate regional development plans.

\section{Introduction}

Beijing-Tianjin-Hebei (BTH) urban agglomeration is one of the top three world-class urban agglomerations in China, with a total area of 216,000 square kilometers $(2.25 \%$ of the country's land area) and a population of about 110 million ( $8.1 \%$ of the country's total population), creating $9.46 \%$ of the gross domestic product (source: China Statistical Yearbook 2019), playing a very important role in China's overall development strategy. However, the economic and social development of BTH urban agglomeration has been achieved via large-scale yet inefficient consumption of energies. In 2014, China's total energy consumption reached 4.003 billion tons of standard coal, among which 442.966 million tons of standard coal were consumed in the BTH region, accounting for $11.07 \%$ of the country's total. China's coal consumption in 2015 was 2.762 billion tons of standard coal, and BTH's share accounted for $13.18 \%$, among which the share of the Hebei province accounted for $81.4 \%$ of the total in the BTH region (source: China Energy Statistical
Yearbook 2016). The superfluous inefficient consumption of energy has led to the deterioration of the ecological environment in the $\mathrm{BTH}$ region. In recent years, China's Air Quality Index (AQI) has frequently stayed beyond the scale, and 6 to 8 of the top 10 most polluted cities in China are located in the BTH region. China's national "13th Five-Year Plan," as well as the "13th Five-Year Plans" of Beijing, Tianjin, and Hebei Prov., clearly put forward the goals of promoting the transformation of energy production and utilization methods, optimizing the energy supply structure, and improving energy efficiency. Energy utilization should meet the needs of economic and social development without destructive impacts on the environment. So, how to improve the ecological total-factor energy efficiency (ETFEE) in this urban agglomeration has become an important issue, which should be considered seriously.

The importance of studying the ETFEE in BTH urban agglomeration under the background of supply-side structural reform can be represented in the following aspects: (1) be conducive to alleviating the pressure of 
energy shortage. Reliable energy supply is a major strategic issue related to the sustainable development for any region. Increasing energy efficiency can help to reduce energy consumption, alleviate the pressure of energy shortage, and contribute to the realization of reliable energy supply in this region. (2) Be helpful to reduce carbon emissions. In 2017, the world's energy-related carbon emissions rebounded, having increased by $1.7 \%$ (the average growth rate in the past decade is only $1.3 \%$ ). According to authoritative reports, China was the biggest contributor to the carbon emission increase [1]. China has been facing the growing international pressure on carbon emission reductions and has set the carbon reduction target for 2030. Carbon emission reduction will undoubtedly be a hard constraint condition on the economic and social development in China [2,3]. Obviously, the increase of the ETFEE in the $\mathrm{BTH}$ region can reduce carbon emissions and loosen the constraint for the longterm development in this region. (3) Be beneficial to protect the ecological environment. Increasing energy efficiency and reducing energy consumption will help to protect the ecological environment in the region. (4) Be conducive to grasping the direction of the energy structural reform. We need a large amount of data and reliable conclusions as the basis of scientific decision-making for the structural reform of the energy supply side. The study on the ETFEE in BTH urban agglomeration can enrich the theory and practice on the energy structural reform. (5) Provide references for other urban agglomerations. China has many urban agglomerations, such as the Pearl River Delta urban agglomeration, Yangtze River Delta urban agglomeration, Chengdu and Chongqing urban agglomeration, and the Middle Reaches of the Yangtze River urban agglomeration. These urban agglomerations may also come up against the similar ETFEE problems during their developments. The research methods and findings of this paper can provide references for these urban agglomerations.

In summary, the study on the ETFEE in BTH urban agglomeration is of great practical and academic values for energy conservation, emission reduction, environmental protection, and even for sustainable development of economy and society in China.

\section{Literature Review}

At present, energy efficiency research methods can be divided into three categories, namely, single-factor energy efficiency method, index analysis method, and total-factor energy efficiency method.

Single-factor energy efficiency is defined as the amount of energy consumption per unit of GDP. Single-factor energy efficiency has some advantages, such as being easy to calculate and make comparison between different regions. However, single-factor energy efficiency also has congenital defects. For example, it is vulnerable to factors such as climate, energy price, and demographic structure [4-6]. In 1997, Nagata proposed the concept of "real energy intensity," which refers to the energy efficiency after removing the influences of the aforementioned factors [7]. Besides, the use of single-factor energy efficiency may lead to the loss of structural information.

Some index analysis methods for energy efficiency have been proposed and applied to energy efficiency research studies. Su et al. [8] investigated the drivers of carbon emission changes of Singapore through a structural decomposition analysis (SDA); Román and Colinet [9], Zhao et al. [10], and $\mathrm{He}$ et al. [11] analyzed the driving forces behind the energy consumption changes via SDA. Zha et al. [12] explored whether the changes in the technology gap are one of the key driving factors of $\mathrm{CO}_{2}$ emissions by index decomposition analysis (IDA); Liu and $\mathrm{Xu}$ [13] used IDA methods to decompose energy intensity change in China's metallurgical industry, while Xie and Lin [14] studied the energy intensity changes in China's food industry. Rüstemoğlu and Andrés [15] explored the energy-related $\mathrm{CO}_{2}$ emissions in Brazil and Russia, and the refined Laspeyres index method was applied, and both aggregated and sectoral changes in $\mathrm{CO}_{2}$ emissions decomposed; Shang et al. [16] analyzed the changing industrial water use in Tianjin through a refined Laspeyres model. González et al. [17] and González [18] used Divisia decomposition to explore the evolution of real energy efficiency in the European Union and the influence that the changes in sectoral composition in most EU economie, respectively. Moreover, Choi and Oh [19] studied the energy efficiency of the manufacturing industry of Korea, and Liao and Wei [20] examined China's aggregate energy consumption by using the Divisia approach. Although there are many improvements in index analysis methods compared with the single-factor energy efficiency method, they still cannot reflect the influences of the substitution effect between various factors on energy efficiency.

In 2006, $\mathrm{Hu}$ and Wang [21] first put forward the concept of total-factor energy efficiency (TFEE) and used the data envelopment analysis (DEA) method to calculate TFEE within the framework of capital, labor, and energy. In essence, TFEE is the ratio of the target energy input to the actual energy input, so calculating the target energy input is the critical step for TFEE calculation. DEA method is a nonparametric frontier method suitable for calculating the target energy input. Although stochastic frontier analysis (SFA) can also be used to calculate TFEE, it is not often chosen because of its function set artificially; otherwise, it may increase the risk of utilizing SFA to some extent. In addition, SFA cannot solve the problem of multi-input and multioutput $[22,23]$. Therefore, after $\mathrm{Hu}$ and Wang, DEA method has been utilized by more and more researchers and has been a mainstream method for TFEE calculation.

Most of the existing literature directly added energy as a production factor into the DEA model and took the calculated efficiency as TFEE without distinguishing the production factors of labor and capital [24, 25]. In this case, the so-called TFEE cannot highlight the characteristics of energy [26]. To solve this problem, Tone [27] proposed a nonradial and nonoriented slack-based measure (SBM) model in 2001. The SBM method can separate the energy efficiency from 
total-factor productivity and obtain the true energy efficiency. Besides, SBM can also consider the input and output slack variables simultaneously. The traditional DEA model does not take undesirable outputs into account. Many studies assumed that outputs were all desirable ones, but it is not true. For example, in a thermal power plant, a large amount of undesirable outputs such as carbon dioxide, sulfur dioxide, and soot is being emitted, while coal is burned and converted to electricity. In 1983, Pittman first incorporated pollution factors into the efficiency model [28]. To sum up, we take the total-factor energy efficiency considering undesirable outputs as ecological total-factor energy efficiency (ETFEE). Since SBM can take energy saving and emission reduction into account simultaneously, we utilize this method in our research.

As for the TFEE in the BTH region in China, some researchers have studied it in recent years. For example, Wang et al. [29] used the DEA model to calculate the TFEE in the BTH region using data from the year 2005 to 2009 and found that technological progress was the leading force in the changing process of TFEE. Feng et al. [30] used the SBM model to measure the energy efficiency in the BTH region, analyzed the influencing factors of energy efficiency, and found that the most significant influencing factors were energy consumption structure, industrial structure, economic development level, and foreign investment. Wang [31] evaluated the energy efficiency in the BTH region by constructing a regional energy efficiency index system and concluded that the coordinated development of energy efficiencies among Beijing, Tianjin, and Hebei Prov. reached a coordinated development interval.

The existing literature on the TFEE in the BTH region has the following shortcomings: (1) the DEA method used in some studies failed to meet the empirical rule of thumb; (2) the effects of undesired outputs were not taken into account in some studies of energy efficiency; (3) almost none of the previous studies has comprehensively studied ETFEE in BTH urban agglomeration in the context of energy supplyside structural reform; and (4) most studies directly take energy structure as one of the factors affecting energy efficiency without considering the lagged effect and dynamic influence between the energy structure and the energy efficiency.

This study intends to make supplements to the existing literature in the following aspects: (1) construct an improved Window-SBM-undesirable model to meet the requirements for calculating the ETFEE in BTH urban agglomeration; (2) measure the recent ETFEE in BTH urban agglomeration scientifically from the perspectives of energy saving and emission reduction with undesirable outputs taken into consideration; (3) study the potential of energy conservation and emission reduction in the BTH urban agglomeration under the background of the energy supply-side structural reform; and (4) analyze the lag effect and dynamic influence relationship between the energy structure and the energy efficiency. The rest of this paper is organized as follows: firstly, the modeling process is given; then, the next part is empirical analysis, including data description and result analysis; and the last part is conclusions.

\section{Modeling Process}

3.1. Window Technology. DEA model should meet the basic rule of thumb: the number of decision-making units (DMUs) should not be less than the product of the number of input variables and that of output variables, and meanwhile, it should not be less than three times the sum of the number of input variables and that of output variables, too [32]. That is,

$$
C \geq \max \{A \times B, 3 \times(A+B)\},
$$

where $A$ and $B$ represent the numbers of input variables and output variables, respectively, and $C$ represents the number of DMUs.

However, the basic rule of thumb cannot be met since there are only three DMUs in this research. To deal with this problem effectively, we combine window technology with the SBM method to establish a Window-SBM model.

The Window-SBM method uses the data of each DMU repeatedly during different periods of efficiency measurement. Firstly, we select the window width $d$ and then get $d \times J$ DMUs in a window ( $J$ is the number of original DMUs). If total length of time is $T$, then the number of DMUs will reach $d \times J \times(T-d+1)$. For each DMU, we establish $T-d+1$ windows for efficiency measurement. We will get $d$ efficiency values for every DMU in the $m$ th window $(m=1,2, \ldots, T-d+1)$. Starting from the time point $t=1$, we can get $d$ efficiency values in the first window, then move to the next time point $t=2$, and so on, till $t=T-d+1$. Finally, the average value of the efficiencies at each time point is taken as the final value of the evaluated DMU efficiency.

3.2. SBM-Undesirable Model. SBM-undesirable model deals with the situations when undesirable outputs exist, by setting the improvements of undesirable outputs in the opposite direction to the desirable outputs, which will result in more good outputs and less bad outputs. The SBM model with undesirable outputs is expressed as follows:

$$
\begin{aligned}
& \min \rho= \frac{1-(1 / m) \sum_{i=1}^{m} s_{i}^{-} / x_{i 0}}{1+\left(1 / q_{1}+q_{2}\right)\left(\sum_{r=1}^{q_{1}} s_{r}^{+} / y_{r 0}+\sum_{t=1}^{q_{2}} s_{t}^{b-} / b_{t 0}\right),}, \\
& \text { s.t. }\left\{\begin{array}{l}
\sum_{j=1}^{n} x_{\mathrm{ij}} \lambda_{j}+s_{i}^{-}=x_{i 0}, \quad(i=1,2, \ldots, m), \\
\sum_{j=1}^{n} y_{\mathrm{rj}} \lambda_{j}-s_{r}^{+}=y_{r 0}, \quad\left(r=1,2, \ldots, q_{1}\right), \\
\sum_{j=1}^{n} b_{\mathrm{tj}} \lambda_{j}+s_{t}^{b-}=b_{t 0}, \quad\left(t=1,2, \ldots, q_{2}\right), \\
\lambda_{j}, s_{i}^{-}, s_{r}^{+}, s_{t}^{b-} \geq 0,
\end{array}\right.
\end{aligned}
$$

where $\rho$ is the efficiency value; $n$ is the number of DMUs; $m$, $q_{1}$, and $q_{2}$ are the numbers of the inputs, the desirable outputs, and the undesirable outputs, respectively; $s_{i}^{-}, s_{r}^{+}$, and 
$s_{t}^{b-}$ are the slack variables of the inputs, the desirable outputs, and the undesirable outputs, respectively; $\lambda_{j}$ are the intensive parameters; $x_{j}, y_{j}$, and $b_{j}$ represent the variables of the inputs, the desirable outputs, and the undesirable outputs of $\mathrm{DMU}_{j}$, respectively; and $x_{0}, y_{0}$, and $b_{0}$ represent the values of the inputs, the desirable outputs, and the undesirable outputs of $\mathrm{DMU}_{0}$, respectively.

From model (2) above, we can see that the slack variables of the inputs and the outputs are put into the objective function of the SBM model, and the inefficiency value can be directly measured when compared with the optimal production frontier. It is in this way that the slack problem gets solved, and accordingly, the efficiency evaluation of the undesirable outputs can be effectively dealt with synchronously.

3.3. Super SBM-Undesirable Model. In order to solve the comparability problem among effective DMUs, this study combines the SBM-undesirable model with the super DEA method to construct a super SBM-undesirable model which is expressed as follows:

$$
\begin{aligned}
& \min \rho=\frac{1+(1 / m) \sum_{i=1}^{m} s_{i}^{-} / x_{i 0}}{1-\left(1 / q_{1}+q_{2}\right)\left(\sum_{r=1}^{q_{1}} s_{r}^{+} / y_{r 0}+\sum_{t=1}^{q_{2}} s_{t}^{b-} / b_{t 0}\right)}, \\
& \operatorname{s.t.}\left\{\begin{array}{l}
\sum_{j=1, j \neq j_{0}}^{n} x_{\mathrm{ij}} \lambda_{j}-s_{i}^{-} \leq x_{i 0}, \quad(i=1,2, \ldots, m), \\
\sum_{j=1, j \neq j_{0}}^{n} y_{\mathrm{rj}} \lambda_{j}+s_{r}^{+} \geq y_{r 0}, \quad\left(r=1,2, \ldots, q_{1}\right), \\
\sum_{j=1, j \neq j_{0}}^{n} b_{\mathrm{tj}} \lambda_{j}+s_{t}^{b-} \leq b_{t 0}, \quad\left(t=1,2, \ldots, q_{2}\right), \\
1-\frac{1}{q_{1}+q_{2}}\left(\sum_{r=1}^{q_{1}}\left(\frac{s_{r}^{+}}{y_{r 0}}\right)+\sum_{t=1}^{q_{2}}\left(\frac{s_{t}^{b-}}{b_{t 0}}\right)\right)>0, \\
\lambda_{j}, s_{i}^{-}, s_{r}^{+}, s_{t}^{b-} \geq 0, \quad\left(j=1,2, \ldots, n ; j \neq j_{0}\right) .
\end{array}\right.
\end{aligned}
$$

The explanations of the parameters in model (3) can be referred to as in model (2). The effectiveness of the energy efficiency in model (3) is determined based on the following rules: (1) if $\rho<1$, then $\mathrm{DMU}_{0}$ is non-DEA-efficient; (2) if $\rho \geq 1$, then $\mathrm{DMU}_{0}$ is DEA-efficient, and the bigger the value, the higher the efficiency.

\section{Empirical Analysis}

4.1. Data Description. The panel data of Beijing, Tianjin, and Hebei Prov. from 2001 to 2016 are selected in this study. The input data include capital, labor, and energy; the output data include GDP and sulfur dioxide emissions, of which sulfur dioxide is taken as an undesirable output (sources: China
Statistical Yearbook and China Energy Statistical Yearbook). The relevant data are described as follows.

(1) Capital: generally speaking, studies involving capital investment should use capital stock as a proxy variable for capital input. However, capital stock data normally are not available in the official statistics released by the Chinese government; China's total capital stock could only be estimated in many literature studies. For example, Zhang et al. [33] put forward the perpetual inventory method to estimate capital stock. As in most literature studies, this study calculates the capital stock data of Beijing, Tianjin, and Hebei Prov. based on the perpetual inventory method proposed by Zhang et al. (2) Labor: the total number of employed people in Beijing, Tianjin, and Hebei Prov. from 2001 to 2016 is used as labor input data. The total number of employed people includes the numbers of people employed in state-owned enterprises, private enterprises, and self-employed businesses. (3) Energy: the total energy consumptions from 2001 to 2016 are used as energy input data. Different from the previous studies, the energy inputs in this study include both primary energy input and secondary energy input. The energies consumed include coal, coke, crude oil, gasoline, kerosene, diesel, fuel oil, natural gas, and electricity. The consumption data of all kinds of energies are converted into data expressed by standard coal before adding them up. (4) GDP: the GDP data from 2001 to 2016 are used as desirable output data. Based on the data of 2001, this study calculates GDP data of Beijing, Tianjin, and Hebei Prov. from 2001 to 2016 at constant prices. (5) Sulfur dioxide emissions: according to Fare et al. [34], sulfur dioxide is the most critical pollutant to affect outputs. Considering the availability of data, this study selects sulfur dioxide as a representative of undesirable outputs.

4.2. Spearman Correlation Test. The Spearman rank correlation coefficient is a distribution-independent rank statistical parameter to measure the strength of the relationship between two variables. Considering that the input and output variables should have a certain correlation, in order to ensure the authenticity of the efficiency measurement, the Spearman correlation test is carried out on the input-output variables in this paper. The Spearman correlation test results of the input-output variables are shown in Table 1 .

From the results in Table 1, all of the correlation coefficients between variables are positive. Except for the correlation coefficient between labor and $\mathrm{SO}_{2}$, all of the correlation coefficients pass the Spearman correlation test at the 0.01 level. The input-output variables conform to the principle of homotropy in the test, which is reasonable and can be further analyzed.

\section{Calculation and Analysis}

5.1. ETFEE and Its Decomposition. The ETFEE values of the BTH region from 2001 to 2016 are figured out based on the nonradial and nonoriented Window-SBM-undesirable model. Since the window technology can result in multiple values of ETFEE in a year, the average of these ETFEE values 
TABLE 1: Spearman correlation test results.

\begin{tabular}{lcc}
\hline Correlation coefficient & $\mathrm{GDP}$ & $\mathrm{SO}_{2}$ \\
\hline Capital & $0.8896^{* *}$ & $0.4427^{* *}$ \\
Labor & $0.9263^{* *}$ & 0.0101 \\
Energy & $0.7870^{* *}$ & $0.6035^{* *}$ \\
\hline
\end{tabular}

${ }^{* *}$ A significant correlation at the 0.01 level (two-tailed).

is taken as the ETFEE value of the evaluated DMU in the corresponding year. The calculation results are shown in Figure 1.

As can be seen from Figure 1, ETFEE in Beijing, Tianjin, and Hebei shows a fluctuating growth trend from 2001 to 2016. Over the same period, Beijing and Tianjin consistently outperformed Hebei. In addition, the value of the ETFEE in Beijing was generally higher than that in Tianjin (except for 2003, 2009, 2010, and 2012). From 2009 to 2010, ETFEE values in the three provincial regions all showed a temporary small decline, which may be related to the economic crisis in 2008. In 2008, the USA subprime mortgage crisis triggered a financial tsunami, and it afterwards developed into a global economic crisis. Due to the lag effect, a local minimum of the energy efficiency curve occurred in 2010. Subsequently, ETFEE rebounded under the stimulus of a series of relevant policies issued by the central government. The ETFEE curves of Beijing and Tianjin both had small fluctuations during the study period, but in the long run, they were still on the rise, and the ETFEE values of the two cities were basically close. The ETFEE in Hebei had been growing steadily from 2001 to 2016, but it was lower than that in Beijing and Tianjin. The superior geographical location makes Hebei benefit from the development of Beijing and Tianjin, which helps to gradually raise the ETFEE of Hebei. The overall average ETFEE value in the $\mathrm{BTH}$ region was higher than that in the Hebei province, but lower than that in Beijing and Tianjin. Obviously, ETFEE in the BTH region is pulled down due to the low values in Hebei. It can be seen that the ETFEE in the Hebei province still has great room for improvement.

The traditional development mode, with characteristics of high energy consumption, high emissions, and high pollution, was facing severe challenges. All these problems can be attributed to the energy consumption structure. Some traditional manufacturing industries, such as iron and steel industry and cement industry, had serious overcapacities, wasting a lot of energies but reaping few benefits. After 2012, the Chinese government carried out supply-side structural reform. During this reform, BTH region shut down a large number of energy-intensive enterprises such as cement, glass, and steel enterprises. That is why the ETFEE curve of Hebei shows a rapid growth trend in this period. Later, in order to cope with the severe haze condition, Beijing, Tianjin, and Hebei implemented policies such as "coal-togas" and "even and odd plates." As a result, the primary energy consumption was greatly reduced, especially in Beijing, the capital of China, where coal was banned in an all-round way. The implementation of a series of measures has indeed raised the ETFEE in the BTH region, which shows that adjusting the energy structure and reducing the primary energy consumption have a certain positive effect on improving energy efficiency.

The ETFEE values in the BTH region are decomposed by the FGNZ decomposition method, and the results are shown in Table 2.

From Table 2, we know that the average technical efficiency (TE) of Beijing, Tianjin, and Hebei Prov. is 1.0170, 0.9708 , and 0.8935 , respectively. That is to say Beijing is DEA-efficient, while Tianjin and Hebei Prov. are non-DEAefficient. From the perspective of pure technical efficiency, the average pure technical efficiencies of Beijing, Tianjin, and Hebei Prov. are 1.1192, 1.1496, and 0.9553, respectively. The technological progress rates of Beijing and Tianjin are $11.92 \%$ and $14.96 \%$ relatively, while that of Hebei Prov. is $-4.47 \%$. Most of the annual pure technical efficiencies of Beijing and Tianjin in the past years are more than 100\% (except for 2004, Beijing), while those of Hebei Prov. are almost less than 100\% (except for 2010, 2014-2016). The conclusion shows that the pure technical efficiency of Hebei Prov. is obviously lower than that of Beijing and Tianjin, which is similar to the conclusion of Liang et al [35]. In terms of scale efficiency, Beijing, Tianjin, and Hebei Prov. are $97.75 \%, 86.60 \%$, and $93.81 \%$ respectively, which indicates that the energy industry scale in these three provincial areas could be further optimized.

5.2. ETFEE and Energy Structure. China relies mainly on fossil energy, and its energy consumption structure is dominated by coal, while petroleum and natural gas account for relatively small proportions. Therefore, in this paper, the consumption ratios of coal, petroleum, and natural gas are selected to represent the energy consumption structure and are recorded as SCOAL, SOIL, and SGAS, respectively. In order to eliminate heteroskedasticity between variables, the logarithms of variables are calculated and expressed as LNETFEE, LNSCOAL, LNSOIL, and LNSGAS. The ADF unit root test and cointegration test show that LNETFEE, LNSCOAL, LNSOIL, and LNSGAS are all first-order integral series. There are long-term cointegration relationships between the ETFEE and the proportion of coal, petroleum, and natural gas. In this paper, the impulse response function is used to describe the 15-period detailed state, and the longterm and short-term relationships between LNETFEE, LNSCOAL, LNSOIL, and LNSGAS are further investigated. In Figures 2-4, the horizontal axis represents the lag periods of impact action, which is 15 , and the vertical axis represents the response caused by the fluctuation of the energy structure. The solid line is the impulse response function, and the dotted lines are the deviation intervals plus or minus twice standard deviations.

Figure 2 shows the dynamic response process of LNSCOAL under an impact of LNETFEE. Facing an impact of ETFEE, SCOAL was 0 in the 1 st period, then began to rise slightly, and gradually declined after reaching the maximum in the 3rd period. It indicates that SCOAL has a positive effect on the ETFEE in the short term. However, in the long run, SCOAL will have a negative effect on the ETFEE, and this negative effect will expand over time. Therefore, China's 


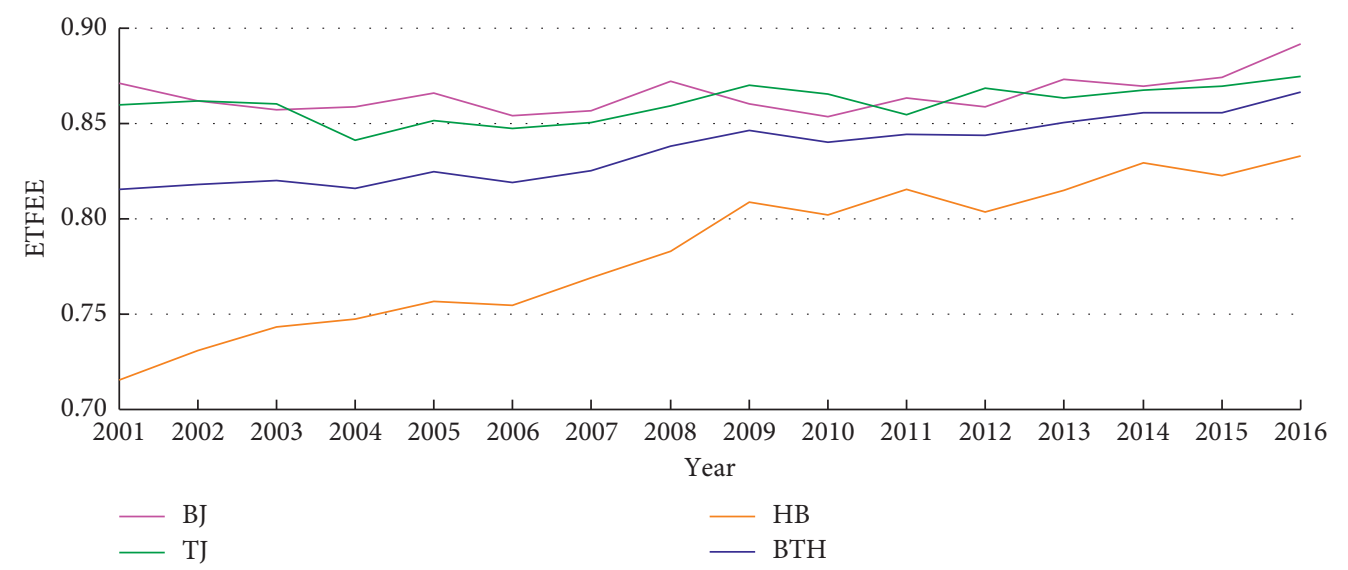

Figure 1: ETFEE in the BTH region.

TABLE 2: Decomposition results of the ETFEE.

\begin{tabular}{|c|c|c|c|c|c|c|c|c|c|}
\hline \multirow{2}{*}{ Year } & \multicolumn{3}{|c|}{ Beijing } & \multicolumn{3}{|c|}{ Tianjin } & \multicolumn{3}{|c|}{ Hebei } \\
\hline & $\mathrm{TE}$ & PTE & SE & $\mathrm{TE}$ & PTE & SE & $\mathrm{TE}$ & PTE & SE \\
\hline 2001 & 1.0941 & 1.1192 & 0.9775 & 0.9735 & 2.0133 & 0.4835 & 0.7662 & 0.7793 & 0.9831 \\
\hline 2002 & 0.9206 & 1.0110 & 0.9106 & 1.0007 & 1.3392 & 0.7473 & 0.7786 & 0.8445 & 0.9220 \\
\hline 2003 & 0.9051 & 1.0601 & 0.8537 & 0.9189 & 1.1465 & 0.8015 & 0.7945 & 0.8758 & 0.9072 \\
\hline 2004 & 0.8685 & 0.9783 & 0.8878 & 0.8800 & 1.0677 & 0.8243 & 0.8139 & 0.8647 & 0.9412 \\
\hline 2005 & 0.9156 & 1.0341 & 0.8854 & 0.8907 & 1.0438 & 0.8533 & 0.8602 & 0.9072 & 0.9482 \\
\hline 2006 & 0.9422 & 1.0654 & 0.8843 & 0.9032 & 1.0575 & 0.8541 & 0.8756 & 0.9208 & 0.9509 \\
\hline 2007 & 0.9976 & 1.0820 & 0.9220 & 0.9278 & 1.0425 & 0.8899 & 0.9067 & 0.9611 & 0.9434 \\
\hline 2008 & 1.0073 & 1.1778 & 0.8552 & 0.9830 & 1.0756 & 0.9139 & 0.9109 & 0.9786 & 0.9308 \\
\hline 2009 & 0.9458 & 1.0272 & 0.9207 & 1.0686 & 1.1676 & 0.9152 & 0.9030 & 0.9262 & 0.9750 \\
\hline 2010 & 1.0345 & 1.0890 & 0.9499 & 1.0599 & 1.1475 & 0.9237 & 0.9761 & 1.0267 & 0.9508 \\
\hline 2011 & 1.0108 & 1.1210 & 0.9017 & 0.9471 & 1.0369 & 0.9134 & 0.8740 & 0.8990 & 0.9722 \\
\hline 2012 & 0.9939 & 1.0218 & 0.9727 & 0.9371 & 1.0254 & 0.9139 & 0.8581 & 0.9078 & 0.9452 \\
\hline 2013 & 1.0649 & 1.0927 & 0.9746 & 0.9542 & 1.0135 & 0.9415 & 0.9336 & 0.9891 & 0.9439 \\
\hline 2014 & 1.0493 & 1.0652 & 0.9850 & 1.0013 & 1.0371 & 0.9655 & 0.9895 & 1.0598 & 0.9336 \\
\hline 2015 & 1.0847 & 1.1141 & 0.9737 & 1.0380 & 1.0868 & 0.9551 & 1.0107 & 1.0785 & 0.9372 \\
\hline 2016 & 1.5151 & 1.5379 & 0.9852 & 1.0486 & 1.0923 & 0.9600 & 1.0445 & 1.2658 & 0.8252 \\
\hline Mean & 1.0170 & 1.1192 & 0.9775 & 0.9708 & 1.1496 & 0.8660 & 0.8935 & 0.9553 & 0.9381 \\
\hline
\end{tabular}

TE, PTE, and SE indicate technical efficiency, pure technical efficiency, and scale efficiency, respectively.

coal-based energy consumption structure needs to be adjusted urgently to reduce the negative effect, thus raising ETFEE.

Figure 3 shows the dynamic response process of LNSOIL under an impact of LNETFEE. Facing an impact of ETFEE, SOIL continued to rise at the beginning and reached the peak in the 4 th period, but then began to decline and reached the bottom in the 15 th period. As time went by, the role of SOIL in improving the ETFEE gradually weakened and even had a negative effect on the ETFEE. At present, the proportion of China's oil consumption is still very low, so increasing the proportion of oil consumption in the short term will help to improve the ETFEE. In the long run, the moderate proportion of petroleum consumption should be maintained, so as to avoid negative effect on the ETFEE.

Figure 4 shows the dynamic response process of LNSGAS under an impact of LNETFEE. Facing an impact of ETFEE, SGAS showed steady upward at the beginning and increased significantly after the 8 th period, which had a positive effect on the ETFEE as a whole. It can be seen that vigorously developing natural gas and increasing the proportion of natural gas in energy consumption will play a significant role in enhancing the ETFEE.

5.3. Energy Inefficiency. The calculation results show that there exist energy inefficiencies in the BTH region, as shown in Figure 5.

Figure 5 shows that energy inefficiencies in Beijing, Tianjin, and Hebei Prov. have been improving. From 2001 to 2016, the energy inefficiency curves are a trumpet-like shape. In 2001, the energy inefficiency of Hebei Prov. was close to 50\%, and then the energy inefficiency curve dropped sharply year by year. In other words, although Hebei's energy efficiency had been improved gradually over the study period, there is still much room for improvement. Beijing's energy efficiency dropped from just over 10 percent in 2001 to about 5 percent in 2016, and Tianjin's dropped from nearly 15 percent to about 5 percent. Tianjin 


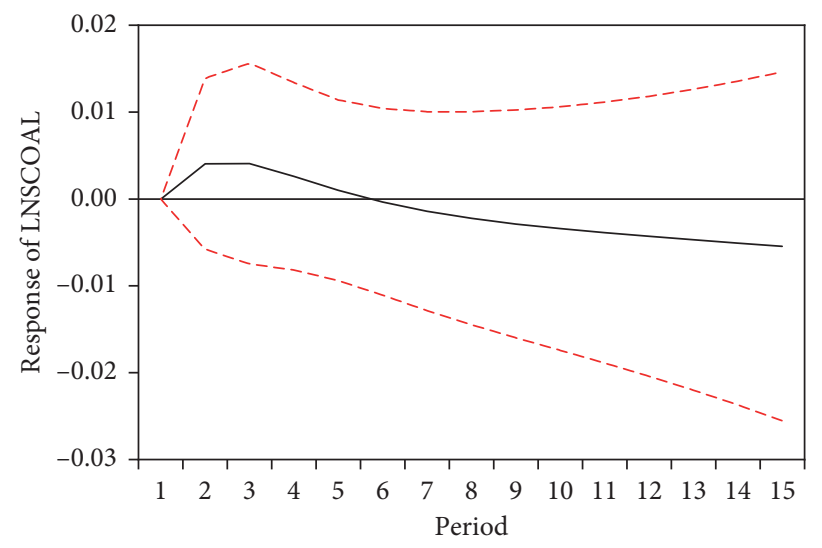

FIGURE 2: Impact response curve of LNSCOAL.

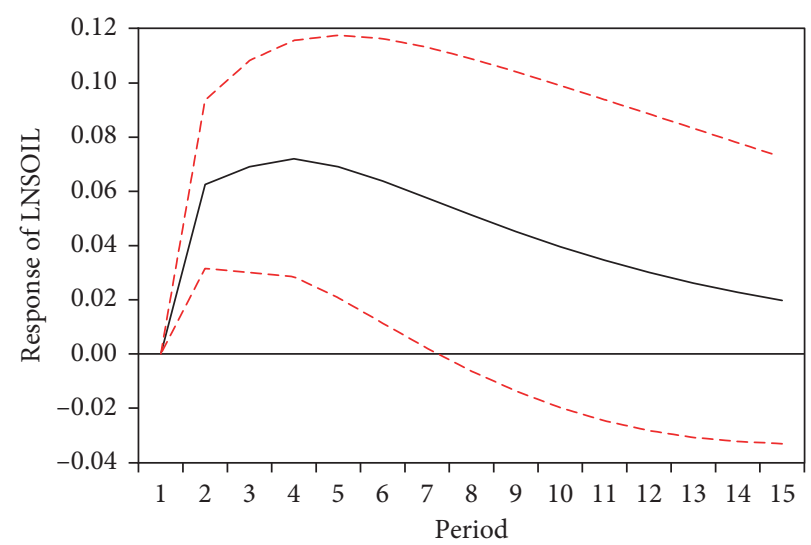

FIgURE 3: Impact response curve of LNSOIL.

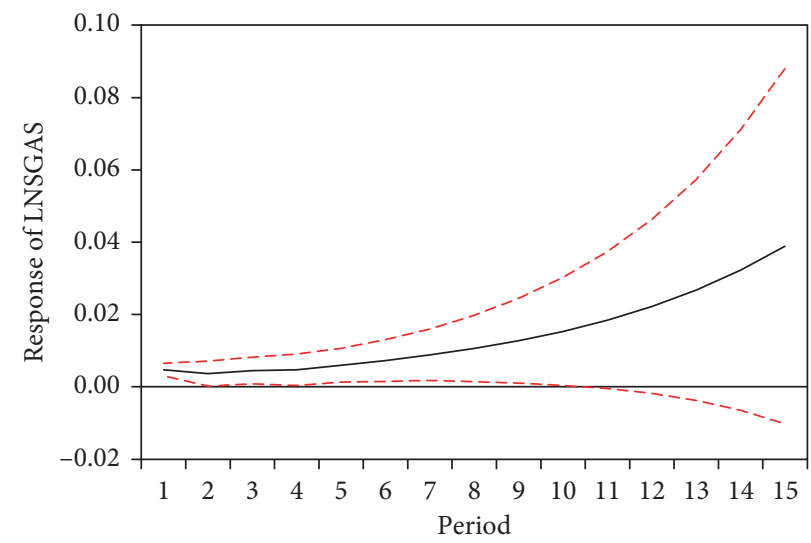

FIGURE 4: Impact response curve of LNSGAS.

and Beijing had similar energy efficiency levels since from 2005 to 2016 (except for 2012). It can be seen that Beijing and Tianjin are more energy-efficient than Hebei. Although the energy inefficiency curve of the BTH region shows a downward trend year by year, the overall energy inefficiency is still high, mainly due to the low energy efficiency of the Hebei province. Therefore, under the guidance of the integrated development strategy of the Beijing-TianjinHebei region, it is necessary to further improve Hebei's energy efficiency so as to reach the overall energy efficiency of the BTH region.

5.4. $\mathrm{SO}_{2}$ Reduction Potential. From the calculation results, the emission reduction potential of sulfur dioxide in the BTH region can be seen, as shown in Figure 6 .

In 2001, the $\mathrm{SO}_{2}$ reduction potential in Hebei Prov. was $82.46 \%$, and then the potential curve fluctuated downward 


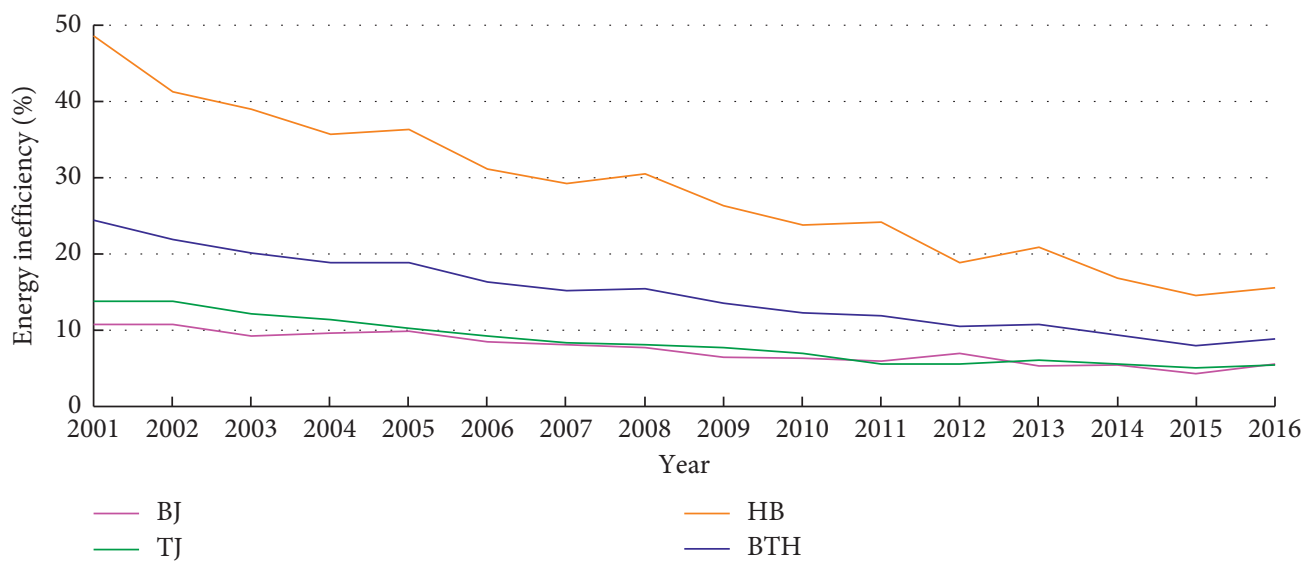

Figure 5: Energy inefficiency.

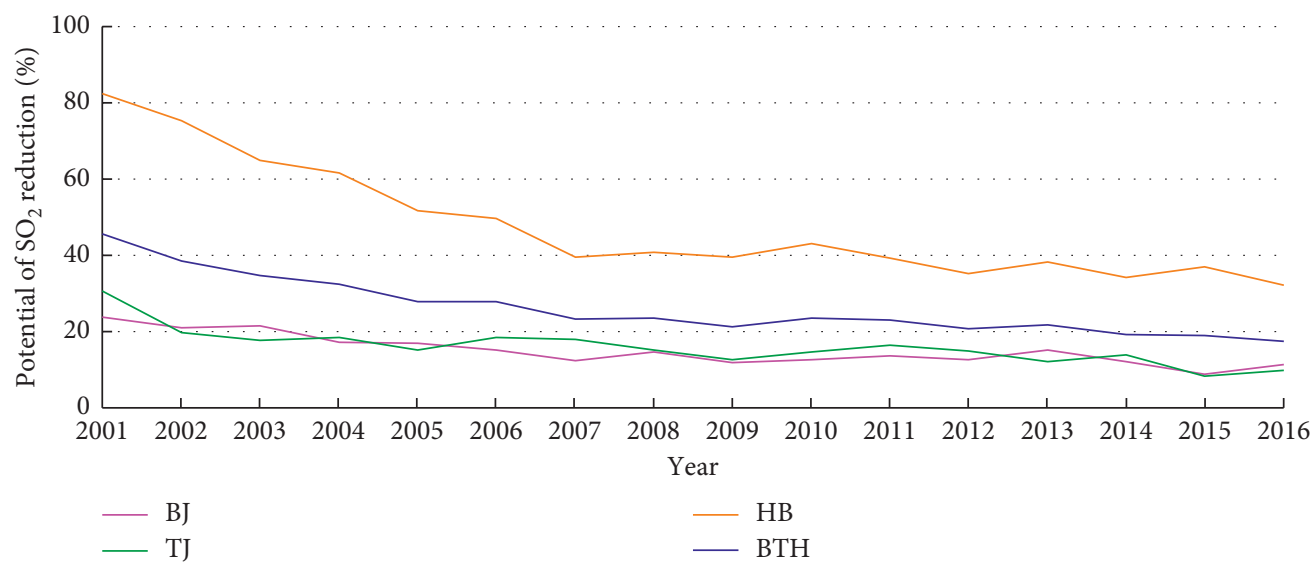

Figure 6: The potential of $\mathrm{SO}_{2}$ reduction.

year by year. In 2010, the $\mathrm{SO}_{2}$ emission reduction potential was $43.05 \%$, and by 2016 , it was close to $5 \%$. The $\mathrm{SO}_{2}$ emission reduction potentials of Beijing and Tianjin fluctuate between $10 \%$ and $20 \%$, indicating that the $\mathrm{SO}_{2}$ emissions of Beijing and Tianjin have been controlled to a certain extent. While Hebei's $\mathrm{SO}_{2}$ reduction potential fell by about 50 percent during the study period, there is still plenty of room to reduce emission compared with Beijing and Tianjin. The $\mathrm{SO}_{2}$ reduction potential in the $\mathrm{BTH}$ region dropped from $45.64 \%$ in 2001 to $17.48 \%$ in 2016 , an overall reduction of nearly $28 \%$. The $\mathrm{SO}_{2}$ emission reduction in the $\mathrm{BTH}$ region is mainly due to the promulgation and implementation of strong energy conservation and environmental protection policies, such as the strict ban on coal in an all-round way, the improvement of oil quality, the large-scale use of clean energies, and the evacuation of polluting enterprises in Beijing and Tianjin.

\section{Conclusions}

Based on the unique characteristics of the BTH region and considering the undesirable output, this study establishes a nonradial and nonoriented Window-SBM-undesirable model to measure the ecological total-factor energy efficiency (ETFEE). Window data processing technology makes the data used in this paper conform to the basic empirical rule of DEA application. The Spearman correlation test shows that the input and output variables selected in this study have strong correlation and can meet the analysis requirements. From the calculation results and analysis, we can see that the developments of the ETFEE in Beijing, Tianjin, and Hebei are unbalanced. The ETFEE of Hebei Prov. has been significantly lower than that of Beijing and Tianjin. The average pure technical efficiencies of Beijing and Tianjin reach 1.1192 and 1.1496, respectively, both higher than Hebei's 0.9553. The pure technical efficiency of the Hebei province needs to be improved. From the perspective of scale efficiency, the energy structures of Beijing, Tianjin, and Hebei Prov. can be further improved. In addition, the impulse response results between the energy structure and the ETFEE show that the proportions of coal and oil will have negative effects on the ETFEE, while that of natural gas will have a positive effect over time.

The Chinese central government has put forward the integrated development strategy of the BTH region and upgraded it to a national strategy. Unremitting efforts should still be paid to increase the ecological total-factor energy efficiency (ETFEE) in the BTH region, and some actions are taken from the following aspects: 
(1) Strengthen the technology transfer and improve the pure technical efficiency of Hebei Prov. It is found that the technical efficiency of Hebei Prov. is significantly lower than that of Beijing and Tianjin. As two international metropolises, Beijing and Tianjin obviously have unique technological superiorities. Under the integrated development strategy of the BTH region, policies should be made to give Beijing and Tianjin incentives to transfer technologies to Hebei Prov. In fact, for the overall harmonious development of the BTH region, Beijing and Tianjin should also try their best to improve the pure technical efficiency of Hebei Prov. as soon as possible.

(2) Work together to optimize the energy supply structure. On the one hand, Beijing and Tianjin should further insist on the utilization of clean energies, such as solar energy, wind energy, and natural gas. On the other hand, these two metropolises should help Hebei Prov. to optimize its energy supply structure. If possible, Beijing and Tianjin could subsidize Hebei Prov. for more clean energies as alternatives to coal. These three areas could coordinate the coal-to-gas supply in order to reduce the total coal consumptions in the BTH region, especially the coal consumption in Hebei Prov.

(3) Jointly develop and apply new clean and low-carbon energy technologies. At the national level, these three areas should take full advantage of the national energy supply-side reform, actively enlist national, financial, and policy support for the development of clean and low-carbon energy technologies, and gradually optimize the energy supply structure. At the local government level, Beijing, Tianjin, and Hebei Prov. should strengthen cooperation in the field of jointly developing and applying new clean and low-carbon energy technologies. For example, jointly develop the new clean coal combustion technology. As we all know, the BTH region is rich in coal, less oil, and less gas, and coal will continue to account for the majority of energy consumption in the long run. The new clean coal combustion technology is an important way to improve energy efficiency and reduce pollutant emission. In addition, recent technological innovations in photovoltaic power generation, wind power generation, and geothermal energy utilization have great potentials in clean energy technology research and development in the future. The three areas can formulate long-term energy development plans, increase official funding for clean energy development and utilization, and guide energy-related research institutions and enterprises to shift energy technology research and production to clean energies.

\section{Data Availability}

The data used to support the findings of this study are available from the corresponding author upon request.

\section{Conflicts of Interest}

The authors declare no conflicts of interest.

\section{Acknowledgments}

The authors are grateful for the support provided by the Hebei Social Science Fund (HB17GL068).

\section{References}

[1] B. P. Global, Global $\mathrm{CO}_{2}$ Emissions from Energy in 2017 Grew by $1.6 \%$, Rebounding from the Stagnant Volumes during 2014-2016, and Faster than the 10-Year Average of 1.3\%, https:/www.bp.com/en/global/corporate/energy-economics/ statistical-review-of-world-energy/co2-emissions.html, 2018.

[2] F. Ren and L. Gu, "Study on transition of primary energy structure and carbon emission reduction targets in China based on Markov chain model and GM $(1,1)$," Mathematical Problems in Engineering, vol. 2016, Article ID 4912935, 8 pages, 2016.

[3] F. Ren and L. Xia, "Analysis of China's primary energy structure and emissions reduction targets by 2030 based on multiobjective programming," Mathematical Problems in Engineering, vol. 2017, Article ID 1532539, 8 pages, 2017.

[4] L. Stankovic, V. Stankovic, J. Liao, and C. Wilson, "Measuring the energy intensity of domestic activities from smart meter data," Applied Energy, vol. 183, pp. 1565-1580, 2016.

[5] H. Yan, "Provincial energy intensity in China: the role of urbanization," Energy Policy, vol. 86, pp. 635-650, 2015.

[6] C. Wang, H. Liao, S.-Y. Pan, L.-T. Zhao, and Y.-M. Wei, "The fluctuations of China's energy intensity: biased technical change," Applied Energy, vol. 135, pp. 407-414, 2014.

[7] Y. Nagata, "The US/Japan comparison of energy intensity: estimating the real gap," Energy Policy, vol. 25, no. 7-9, pp. 683-691, 1997.

[8] B. Su, B. W. Ang, and Y. Li, "Input-output and structural decomposition analysis of Singapore's carbon emissions," Energy Policy, vol. 105, pp. 484-492, 2017.

[9] R. Román-Collado and M. J. Colinet, "Is energy efficiency a driver or an inhibitor of energy consumption changes in Spain? two decomposition approaches," Energy Policy, vol. 115, pp. 409-417, 2018.

[10] N. Zhao, L. Xu, A. Malik, X. Song, and Y. Wang, "Interprovincial trade driving energy consumption in China," Resources, Conservation and Recycling, vol. 134, pp. 329-335, 2018.

[11] H. He, C. J. Reynolds, L. Li, and J. Boland, “Assessing net energy consumption of Australian economy from 2004-05 to 2014-15: environmentally-extended input-output analysis, structural decomposition analysis, and linkage analysis," Applied Energy, vol. 240, pp. 766-777, 2019.

[12] D. Zha, G. Yang, and Q. Wang, "Investigating the driving factors of regional $\mathrm{CO}_{2}$ emissions in China using the IDAPDA-MMI method," Energy Economics, vol. 84, Article ID 104521, 2019.

[13] B. Lin and M. Xu, "Quantitative assessment of factors affecting energy intensity from sector, region and time perspectives using decomposition method: a case of China's metallurgical industry," Energy, vol. 189, Article ID 116280, 2019.

[14] X. Xie and B. Lin, "Understanding the energy intensity change in China's food industry: a comprehensive decomposition method," Energy Policy, vol. 129, pp. 53-68, 2019. 
[15] H. Rüstemoğlu and A. R. Andrés, "Determinants of $\mathrm{CO}_{2}$ emissions in Brazil and Russia between 1992 and 2011: a decomposition analysis," Environmental Science \& Policy, vol. 58, pp. 95-106, 2016.

[16] Y. Shang, S. Lu, X. Li et al., "Drivers of industrial water use during 2003-2012 in Tianjin, China: a structural decomposition analysis," Journal of Cleaner Production, vol. 140, pp. 1136-1147, 2017.

[17] P. Fernández González, M. Landajo, and M. J. Presno, "The Divisia real energy intensity indices: evolution and attribution of percent changes in 20 European countries from 1995 to 2010," Energy, vol. 58, pp. 340-349, 2013.

[18] P. F. González, "Exploring energy efficiency in several European countries: an attribution analysis of the Divisia structural change index," Applied Energy, vol. 137, pp. 364374, 2015.

[19] K.-H. Choi and W. Oh, "Extended divisia index decomposition of changes in energy intensity: a case of Korean manufacturing industry," Energy Policy, vol. 65, pp. 275-283, 2014.

[20] H. Liao and Y.-M. Wei, "China's energy consumption: a perspective from Divisia aggregation approach," Energy, vol. 35 , no. 1 , pp. $28-34,2010$.

[21] J.-L. Hu and S.-C. Wang, "Total-factor energy efficiency of regions in China," Energy Policy, vol. 34, no. 17, pp. 3206-3217, 2006.

[22] Y. x. He, L. f. Yang, W. h. Yang, Y. j. Wang, and Y. Zhang, "Evaluation of power input efficiency for China's typical cities based on the DEA and SFA models," International Journal of Global Energy Issues, vol. 32, no. 4, pp. 350-360, 2009.

[23] A. Fetanat and G. Shafipour, "A hybrid method of LMDI, symmetrical components, and SFA to estimate the distribution of energy-saving potential with consideration of unbalanced components in decomposition analysis," Energy Efficiency, vol. 10, no. 4, pp. 1041-1059, 2017.

[24] M.-C. Chang, "A comment on the calculation of the totalfactor energy efficiency (TFEE) index," Energy Policy, vol. 53, pp. 500-504, 2013.

[25] J.-P. Liu, Q.-R. Yang, and L. He, "Total-factor energy efficiency (TFEE) evaluation on thermal power industry with DEA, malmquist and multiple regression techniques," Energies, vol. 10, no. 7, p. 1039, 2017.

[26] B. Wang, J. Zhang, and H. Zhang, "Total-factor energy efficiency and influencing factors across provinces in China in the presence of environmental regulation," Economic Review, vol. 4, pp. 31-43, 2011.

[27] K. Tone, "Dealing with undesirable outputs in DEA: a slacksbased measure (SBM) approach," in Proceedings of the North American Productivity Workshop 2004, Toronto, Canada, June 2004.

[28] R. W. Pasurka, "Multilateral productivity comparisons with undesirable outputs," The Economic Journal, vol. 93, no. 372, pp. 883-891, 1983.

[29] X. Wang, M. Meng, J. Liu et al., "Study on total factor energy efficiency of Beijing-Tianjin-Hebei metropolitan region under the constraint of carbon emission," Journal of Industrial Technological Economics, vol. 32, no. 1, pp. 11-19, 2013.

[30] B. Feng and X. Wang, "Research on energy efficiency considering the haze effect in Beijing-Tianjin-Hebei metropolitan region," Journal of Arid Land Resources and Environment, vol. 29, no. 10, pp. 1-7, 2015.

[31] S. Wang, "Research on the difference and the coordination of Jing-Jin-Ji's energy efficiency in perspective of green development," Forum on Science and Technology in China, vol. 10, pp. 96-101, 2016.

[32] W. W. Cooper, Data Envelopment Analysis: A Comprehensive Text with Models, Applications, References and DEA-Solver Software, Springer Science \& Business Media, New York, NY, USA, 2nd edition, 2007.

[33] J. Zhang, G. Wu, and J. Zhang, "The estimation of China's provincial capital stock: 1952-2000," Economic Research Journal, vol. 10, pp. 35-44, 2004.

[34] R. Färe, S. Grosskopf, and C. A. Pasurka Jr., "Potential gains from trading bad outputs: the case of U.S. electric power plants," Resource and Energy Economics, vol. 36, no. 1, pp. 99-112, 2014.

[35] Y. Liang, D. X. Niu, W. W. Zhou et al., "Decomposition analysis of carbon emissions from energy consumption in Beijing-Tianjin-Hebei, China: a weighted-combination model based on logarithmic mean divisia index and Shapley value," Sustainability, vol. 10, no. 7, p. 2535, 2018. 